12 Rigby K. Peer relations at school and the health of adolescents. Youth Stud Aust 1998; 17:13-7.

13 Rigby K. What children tell us about bullying in schools. Child Aust 1997;22:28-34.

14 Dawkins J. Bullying in schools: doctors' responsibilities. BMJ 1995;310:274-5.

15 Olweus D. Bullying at school. Oxford: Blackwell, 1993

16 Rigby K. Bullying in Australian schools-and what to do about it. Melbourne, NSW: Australian Council for Educational Research, 1996.

17 Whitney I, Smith PK. A survey of the nature and extent of bullying in junior/middle and secondary schools. Educ Res 1993;35:3-25.

18 Boulton MJ, Underwood K. Bully/victim problems among middle school children. Br J Educ Psychol 1992;62:73-87.
19 Jessor R, Jessor SL. Problem behaviour and psychosocial development. A long itudinal study of youth. New York: Academic, 1977.

20 Bauman A, Hogan A, McLellan L, Rissel C, Mayne D, Gill L, et al. Health behaviours of New South Wales school students:report of the NSW health behaviour of school students (NSW HBSS) survey, 1996. Sydney, NSW: National Centre for Health Promotion, 1998.

21 Eltinge JL, Sribney WM. Versions of mlogit, ologit, and oprobit for survey data. Stata Stat Bull 1997:40:39-42.

22 Nutbeam D, Smith C, Moore L, Bauman A. Warning! Schools can damage your health: alienation from school and its impact on behaviour. J Paediatr Child Health 1993;29(suppl.1):25-30S.

(Accepted 4 May 1999)

\title{
Bullying, depression, and suicidal ideation in Finnish adolescents: school survey
}

\author{
Riittakerttu Kaltiala-Heino, Matti Rimpelä, Mauri Marttunen, Arja Rimpelä, Päivi Rantanen
}

\section{Editorial by \\ Chesson and p 344 \\ University of \\ Tampere, Tampere \\ School of Public \\ Health, Box 607, \\ 33101 Tampere, \\ Finland \\ Riittakerttu \\ Kaltiala-Heino \\ senior assistant \\ professor \\ Arja Rimpelä \\ professor \\ National Research and Development \\ Centre for Welfare \\ and Health, \\ Box 220, 00531 \\ Helsinki, Finland \\ Matti Rimpelä \\ professor \\ Department of \\ Mental Health and \\ Alcohol Research, \\ National Public \\ Health Institute, \\ Mannerheimintie \\ 166, 00300 Helsinki \\ Mauri Marttunen \\ senior researcher \\ Tampere University Hospital, \\ Department of \\ Adolescent \\ Psychiatry, \\ Box 2000, \\ 33521 Tampere \\ Päivi Rantanen \\ professor}

Correspondence to:

R Kaltiala-Heino

merihe@uta.fi

BMJ 1999;319:348-51

\begin{abstract}
Objective To assess the relation between being bullied or being a bully at school, depression, and severe suicidal ideation.

Design A school based survey of health, health behaviour, and behaviour in school which included questions about bullying and the Beck depression inventory, which includes items asking about suicidal ideation.

Setting Secondary schools in two regions of Finland. Participants 16410 adolescents aged 14-16.

Results There was an increased prevalence of depression and severe suicidal ideation among both those who were bullied and those who were bullies. Depression was equally likely to occur among those who were bullied and those who were bullies. It was most common among those students who were both bullied by others and who were also bullies themselves. When symptoms of depression were controlled for, suicidal ideation occurred most often among adolescents who were bullies.

Conclusion Adolescents who are being bullied and those who are bullies are at an increased risk of depression and suicide. The need for psychiatric intervention should be considered not only for victims of bullying but also for bullies.
\end{abstract}

\section{Introduction}

About 1 in 10 schoolchildren report being bullied weekly at school. ${ }^{1-4}$ Boys are involved in bullying, both as victims and as bullies, more often than girls. Primary school children are more likely to be victims of bullying than adolescents, but the number of bullies tends to remain constant between primary school and secondary school. ${ }^{2} 3$

The possible association between being bullied and the risk of suicide has been recognised by adolescent psychiatrists, ${ }^{5}$ but epidemiological studies have not assessed the correlation. Salmon et al found an association between being bullied and being depressed. ${ }^{6}$ In children, being bullied has been associated with an increase in psychological and psychosomatic symptoms. Williams et al found that children who were frequently bullied at school were more likely to wet their beds, have difficulty sleeping, and have headaches and abdominal pain. ${ }^{7}$ Kumpulainen et al found an association between involvement in bullying (being bullied or being a bully) and a number of behavioural and psychological symptoms including depression in children in primary school. ${ }^{8}$ Anxiety, a fear of going to school, feelings of being unsafe and unhappy at school, and low self esteem have all been reported to be consequences of repeatedly being bullied. ${ }^{2}{ }^{9}$ Depression has also been linked to being bullied. ${ }^{10}$

Being a bully in childhood and adolescence has been associated with delinquency in adulthood. Being bullied has been associated with poorer perceived health, depression, and with mental disorders in adulthood. ${ }^{11}$

The aim of this study was to investigate the association between bullying, depression, and severe suicidal ideation among adolescents aged 14-16 in Finland.

\section{Participants and methods}

The school health promotion study is a classroom survey focusing on adolescent health, health behaviour, and behaviour in school; it has been carried out annually in Finland every April since 1995. The health promotion study has been approved by the ethical committee of Tampere University Hospital.

In 1997, students in the 8th and 9th grades of secondary school (ages 14-16 years) in two regions in Finland (Vaasa and Pirkanmaa) participated in the study. Out of a total of 20213 pupils in these schools, 2570 (13\%) were absent on the day of the survey. Altogether, 17643 pupils $(87 \%)$ returned the questionnaire $(8695$ girls, 8948 boys). A total of 1179 students (6.7\%) gave incomplete responses on the Beck inventory and their questionnaires were excluded from the analysis. An additional 54 respondents did not answer the questions about bullying and were also excluded from the analysis. We were thus able to analyse the responses of 16410 students ( $81 \%$ of the target population, $93 \%$ of those present at school).

Involvement in bullying either as a bully or as the person being bullied was evaluated using two questions derived from a World Health Organisation study on youth health. ${ }^{12}$ The subject was introduced as follows:

The next questions are about bullying. We say a pupil is being bullied when another pupil, or a group of pupils, says or does nasty and unpleasant things to him or her. It is also bullying when a pupil is teased repeatedly in a way he or she 
Table 1 Involvement in bullying by sex. Values are numbers (percentages)

\begin{tabular}{lcc}
\hline No participation & Girls & Boys \\
\hline Bully or bullied less than weekly & $4418(54)$ & $2395(29)$ \\
\hline Frequently acts as bully & $3159(39)$ & $4480(55)$ \\
\hline Frequently bullied & $196(2)$ & $705(9)$ \\
\hline Frequently both bully and bullied & $373(5)$ & $464(6)$ \\
\hline Total & $50(1)$ & $170(2)$ \\
\hline
\end{tabular}

doesn't like. But it is not bullying when two pupils of about the same strength quarrel or fight.

The students were asked how frequently they had been bullied during the current school term (from the beginning of January until the end of May) and how frequently they had bullied others. They were asked to indicate whether these actions had occurred many times a week, about once a week, less frequently, or not at all. Those who bullied others at least once a week were classed as frequently being bullies; those who were bullied at least once a week were classed as frequently being bullied. Respondents were classed as not participating in bullying or being bullied, as being bullied or being a bully less than weekly, as frequently acting as a bully and not being bullied, as frequently being bullied and not a bully, or as frequently being both bullied and a bully.

Depression was measured using a modified, 13 item version of the Beck depression inventory ${ }^{13}{ }^{14}$ which had been validated in Finnish. ${ }^{15}$ The Beck inventory has been shown to be a valid measure for detecting depression among adolescents. ${ }^{16}$ It has good psychometric properties in this population. ${ }^{17}$ Students who scored from 0 to 7 were classed as having no depression or mild depression, and those who had scores of 8 to 39 were classed as having moderate to severe depression. ${ }^{13}$

One of the items on the inventory asks about thoughts of self harm. We classed the students as having severe suicidal ideation if they chose either "I have definite plans about committing suicide" or "I would kill myself if I had the chance."

The sociodemographic variables evaluated were age, sex, years since moving to current area, educational level attained by parents, whether one or both parents had been unemployed during the past 12 months, and family structure (whether the adolescent was living with both parents, with one parent, with a step-parent, or apart from the parents). School performance was measured using the child's grade point average; perceived lack of social support from parents, friends, and teachers were used as independent variables. Grade point average and perceived social support have been shown to be determinants of depression in the sample studied (unpublished data). Age and grade point average were analysed as continuous variables, others were dichotomised.

Incomplete responses to the Beck inventory occurred more often among boys (7.8\% (698/8948) $v$ $5.5 \%$ (481/8695), $\mathrm{P}<0.0001)$. The item most frequently unanswered was the item about suicidal ideation which was omitted by $4.9 \%(438 / 8948)$ of boys and 3.7\% (322/8695) of girls.

Associations between bullying and depression (dichotomous variables) and severe suicidal ideation were tested using $\chi^{2}$. Multivariate associations were tested with logistic regression using depression and severe suicidal ideation as dependent variables. The models were fitted using a stepwise forward method starting from an empty model. When using depression as a dependent variable, sex, age, and involvement in bullying (being bullied or being a bully) were tested first. Other variables were added later. When severe suicidal ideation was used as a dependent variable, logistic regression was carried out in three steps. Firstly, sex, age, and involvement in bullying were analysed. Secondly, depressive symptoms (defined as the total score of items on the Beck inventory excluding those on suicidal ideation) were added to the analysis. Finally, the other independent variables were included.

\section{Results}

Five per cent $(373 / 8196)$ of the girls and $6 \%$ (464/8214) of the boys had been bullied weekly during the current school term. Two per cent (196/8196) of the girls and $9 \%(705 / 8214)$ of the boys reported that they had bullied others at least weekly (table 1 ).

Eleven per cent $(915 / 8196)$ of the girls and $6 \%$ $(508 / 8214)$ of the boys were classed as being moderately to severely depressed. Severe suicidal ideation was reported by $2 \%(197 / 8196)$ of girls and $2 \%$ $(170 / 8214)$ of boys.

Depression and severe suicidal ideation were more common among those respondents who were being bullied or who were bullies. Depression occurred equally frequently among those who were bullied and those who were bullies, and it was most common among those who were both bullied by others and were also bullies themselves. Among girls, severe suicidal ideation was associated with frequently being bullied or being a bully, and for boys it was associated with being a bully (table 2 ).

The association between depression and involvement in bullying (being bullied or being a bully) persisted in multivariate analyses. After adjusting for age and sex, the highest risk of depression was seen among those students who were both bullied and were also bullies (odds ratio 9.4); the next highest risk was seen among those who were bullied (odds ratio 5.1). The odds ratio among bullies was 4.5 (table 3 ). Fitting other demographic and social variables that correlate with depression into the model confirmed the association.

Involvement in bullying persisted as a risk for severe suicidal ideation in the multivariate analysis. After adjusting for age and sex, the highest risk of severe suicidal ideation was seen among students who were both bullied and were also bullies (odds ratio 12.1). The next highest risk was among those who were bullies (odds ratio 8.7). The odds ratio for those who

Table 2 Prevalence of moderate to severe depression and severe suicidal ideation as measured by Beck depression inventory among 16410 adolescents who were involved in bullying (being bullied or being a bully) in Finland. Values are percentages (proportions)

\begin{tabular}{|c|c|c|c|c|c|c|}
\hline & \multicolumn{6}{|c|}{ Involvement in bullying } \\
\hline & $\begin{array}{c}\text { No } \\
\text { participation }\end{array}$ & $\begin{array}{l}\text { Bully or bullied } \\
\text { less than weekly }\end{array}$ & $\begin{array}{l}\text { Frequently } \\
\text { acts as bully }\end{array}$ & $\begin{array}{c}\text { Frequently } \\
\text { bullied }\end{array}$ & $\begin{array}{l}\text { Frequently both } \\
\text { bully and bullied }\end{array}$ & $P$ value \\
\hline \multicolumn{7}{|c|}{ Depression } \\
\hline Girls & $8(333 / 4418)$ & $13(412 / 3159)$ & $26(50 / 196)$ & $26(98 / 373)$ & $44(22 / 50)$ & $<0.001$ \\
\hline Boys & $3(72 / 2395)$ & $5(232 / 4480)$ & $13(92 / 705)$ & $16(73 / 464)$ & $23(39 / 170)$ & $<0.001$ \\
\hline \multicolumn{7}{|c|}{ Suicidal ideation } \\
\hline Girls & $1(55 / 4418)$ & $3(93 / 3159)$ & $8(16 / 196)$ & $8(29 / 373)$ & $8(4 / 50)$ & $<0.001$ \\
\hline Boys & $1(23 / 2395)$ & $1(56 / 4480)$ & $8(55 / 705)$ & $4(18 / 464)$ & $11(18 / 170)$ & $<0.001$ \\
\hline
\end{tabular}


Table 3 Odds ratios for the final models of association between involvement in bullying (being bullied or being a bully) and risk of depression and severe suicidal ideation

\begin{tabular}{|c|c|c|}
\hline & \multicolumn{2}{|c|}{ Odds ratio $(95 \% \mathrm{Cl})$} \\
\hline & Depression & Severe suicidal ideation \\
\hline \multicolumn{3}{|l|}{ Involvement in bullying: } \\
\hline No participation & 1.0 & 1.0 \\
\hline Bully or bullied less than weekly & $1.5(1.3$ to 1.8$)$ & $1.4(1.0$ to 1.9$)$ \\
\hline Frequently acts as bully & $2.8(2.2$ to 3.7$)$ & $4.0(2.6$ to 6.4$)$ \\
\hline Frequently bullied & $4.2(3.3$ to 5.3$)$ & 2.1 (1.3 to 3.4$)$ \\
\hline Frequently both bully and bullied & $6.3(4.2$ to 9.5$)$ & 2.5 (1.0 to 6.2$)$ \\
\hline Female sex & $4.0(3.4$ to 4.6$)$ & $P>0.05$ \\
\hline \multicolumn{3}{|l|}{ Family structure: } \\
\hline Lives with both parents & 1.0 & 1.0 \\
\hline Has a step-parent & 1.0 & $1.5(1.0$ to 2.2$)$ \\
\hline Lives with one parent & $1.3(1.1$ to 1.7$)$ & $0.9(0.5$ to 1.4$)$ \\
\hline Lives apart from parents & $1.8(1.0$ to 7.4$)$ & 2.5 (1.0 to 6.3$)$ \\
\hline \multicolumn{3}{|l|}{ Years since moving to area: } \\
\hline$\geqslant 10$ & 1.0 & \multirow{4}{*}{$P>0.05$} \\
\hline$\geqslant 5-9$ & $1.2(0.8$ to 1.3$)$ & \\
\hline $1-4$ & $1.2(1.0$ to 1.5$)$ & \\
\hline$<1$ & $1.6(1.1$ to 2.3$)$ & \\
\hline \multicolumn{3}{|l|}{ Lacking social support from: } \\
\hline Parents & $3.0(2.6$ to 3.4$)$ & 1.7 (1.3 to 2.3$)$ \\
\hline Teachers & $2.0(1.7$ to 2.4$)$ & $P>0.05$ \\
\hline Peers & $2.2(1.9$ to 2.7$)$ & $0.7(0.4$ to 1.0$)$ \\
\hline Depressive symptoms & Not tested & $1.2(1.2$ to 1.2$)$ \\
\hline
\end{tabular}

were bullied was 5.7. When depressive symptoms were added to the analysis, the highest risk of severe suicidal ideation was, however, seen among those who were bullies (odds ratio 4.4); the next highest risk was among those who were both bullied and were also bullies (odds ratio 3.1). The odds ratio for those who were bullied was 2.5. After other determinants of depression were added to the final model, the greatest risk of severe suicidal ideation was detected among bullies, followed by those who were both bullied and were also bullies, and then by those who were bullied (table 3).

\section{Discussion}

Methodological considerations

This study provides a good opportunity to assess cross sectional relations between being bullied or being a bully, self reported depression, and severe suicidal ideation. The sample is large and representative of the mid-adolescent population in Finland. More than 99\% of children and adolescents aged 7 to 16 attend primary and secondary school. The participation rate for the survey was high. However, psychological problems, depression, and experiences of being a bully or being bullied may be more common among those pupils who were absent. Therefore, the prevalences of bullying, depression, and severe suicidal ideation detected in this study are likely to be underestimates.

The 13 item Beck inventory measures the respondent's own perception of her or his depressive symptoms but it is not a diagnostic instrument for depressive disorders. Because the inventory measures a psychological state we could not assess the duration of depressive symptoms. However, severe depressive symptoms in adolescents are likely to be comparatively persistent. ${ }^{18} \mathrm{To}$ avoid bias due to normal mood changes in adolescence, we dichotomised the depression score to moderately or severely depressed versus no depression or mildly depressed. In the multivariate analyses that studied the association between bullying and severe suicidal ideation, we used depressive symptoms as a total score but we excluded the item on suicidal ideation.

Transient death wishes and non-specific suicidal ideation have been reported to be comparatively common during adolescence. ${ }^{19}$ Therefore, only responses indicating severe suicidal ideation with an intent were included in the analyses.

\section{Bullying and mental health}

Depression and severe suicidal ideation are strongly linked to being bullied or to acting as a bully. Even an infrequent involvement in bullying (being bullied or being a bully) increases the likelihood of severe suicidal ideation, independent of depression.

Being bullied frequently is likely to be a considerable source of stress. Depression among those who were frequently bullied might be expected. However, adolescents who are depressed may also attract negative attention from their peers. Previous research suggests that compared with their peers, those who are bullied are more introverted, less assertive, and are overinvolved in their families. ${ }^{20}$ Victims also tend to be rejected by peers. ${ }^{91}$ Depression could thus be both a result of and a reason for being bullied. A longitudinal design is necessary to study causality. However, in this study severe suicidal ideation was increased among those who were bullied regardless of whether they were depressed. This emphasises the stressful nature of being bullied and highlights the importance of taking action to stop bullying.

Although the association between being a bully and depression has not received attention in previous research, bullies have been shown to have certain mental health problems. Being a bully has been associated with juvenile delinquency, alcohol misuse, violence in adulthood, and criminal behaviour. ${ }^{2022}$ The social background of bullies also suggests that they are vulnerable to psychiatric morbidity. Being a bully has been associated with rejection by peers and social isolation. ${ }^{19}$ In bullies' families, more emotional distance between family members, a lack of warmth, and inconsistent discipline for children has been noted. ${ }^{20}$ Bullies thus need support for normal development to proceed, and any interventions should also recognise the role of depressive disorders in the background of their behaviour.

The role of the adolescent remains constant in the long process of being bullied or being a bully. ${ }^{23}$ The

\section{Key messages}

- About 1 in 10 schoolchildren report being bullied weekly at school

- Adolescents who are bullied or who are bullies have an increased risk of depression and suicidal ideation

- Bullies are often as depressed as those who are bullied, and suicidal ideation is even more common among bullies

- Interventions aimed at reducing bullying in schools, as well as psychiatric assessment and treatment of bullies and those who are bullied, might also prevent depression and suicidal ideation 
strong association between being a bully or being bullied, depression, and severe suicidal ideation highlights the importance of further investigations into the social, psychological, and environmental factors associated with bullying.

\section{Conclusion}

Teachers and clinicians should recognise that being bullied or being a bully are signs of an increased risk of depression and suicidal behaviour among adolescents. Adolescents should be asked if they are involved in bullying either as a victim or as a bully. Whether an intervention is needed to treat depression should be assessed among both bullies and those who are being bullied. A cross disciplinary approach is needed to identify effective interventions to prevent bullying and depression and to reduce the risk of suicide while keeping in mind the close association between these phenomena.

Contributors: RK-H developed and coordinated the formulation of the primary study hypothesis, discussed the core ideas, and participated in planning the collection of data, analysing the data, and writing the paper. MR initiated the school health promotion study and the inclusion of mental health questions in the survey, he discussed the core ideas, and participated in analysing the data and writing the paper. MM brought to the discussion about the core ideas of the study his expertise as a researcher on adolescent suicide and depression, and participated in designing the study, analysing the data, and writing the paper. AR discussed the core ideas of the school health promotion study as well as of this present report, and brought to the process her expertise as an epidemiologist; she also helped analyse the data and write the paper. PR discussed the core ideas of the study and supported the formulation of the hypothesis from the point of view of a clinical adolescent psychiatrist, and participated in writing the paper. MR will act as guarantor for the paper

Funding: None.

Competing interests: None declared.

1 Perry GD, Kusel SJ, Perry CL. Victims of peer aggression. Dev Psychol 1988;24:807-14.

2 Boulton MJ, Underwood K. Bully/victim problems among middle school children. Br J Educ Psychol 1992;62:73-87.

3 Whitney I, Smith PK. A survey of the nature and extent of bullying in junior/middle and secondary schools. Educ Res 1993;35:3-25.
4 Rigby K, Slee PT. Dimensions of interpersonal relations among Australian children and implications for psychological well-being. J Soc Psycho 1992;133:33-42.

5 Rutter M, Taylor E, Hersov M, eds. Child and adolescent psychiatry: modern approaches. 3rd ed. Oxford: Blackwell Science, 1994.

6 Salmon G, James A, Smith DM. Bullying in schools: self reported anxiety, depression and self esteem in secondary school children. BMJ 1998;317:924-5.

7 Williams K, Chambers M, Logan S, Robinson D. Association of common health symptoms with bullying in primary school children. BMJ 1996;313:17-9.

8 Kumpulainen K, Räsänen E, Henttonen I, Almqvist F, Kresanov K, Linna S-L, et al. Bullying and psychiatric symptoms among elementary schoolage children. Child Abuse Negl (in press).

9 Boulton MJ, Smith PK. Bully/victim problems in middle-school children: stability, self-perceived competence, peer perceptions and peer acceptance. Br J Dev Psychol 1994;12:315-29.

10 Byrne BJ. Bullies and victims in a school setting with reference to some Dublin schools. Irish J Psychol 1994;15:574-86.

11 Slee PT. Bullying: health concerns of Australian secondary schoo students. Int J Adolescence Youth 1995;5:215-24.

12 King A, Wold B, Tudor-Smith C, Harel Y. The health of youth: a cross-national survey. Copenhagen, Denmark: WHO Regional Publications, 1996. (European series No 69.)

13 Beck AT, Beck RW. Screening depressed patients in family practice: a rapid technic. Postgrad Med 1972;52:81-5

14 Beck AT, Rial WY, Rickels K. Short form of depression inventory: crossvalidation. Psychol Rep 1974;34:1184-6.

15 Raitasalo R. Elämänhallinta sosiaalipolitiikan tavoitteena. Kansaneläkelaitos, Sosiaali-ja terveysturvan tutkimuksia 1. Helsinki: Kelan omatarvepaino; 1995.

16 Bennett DS, Ambrosini PJ, Bianchi M, Barnett D, Metz C, Rabinovich H Relationship of Beck depression inventory factors to depression among adolescents. J Affect Disord 1997;45:127-34.

17 Kaltiala-Heino R, Rimpelä M, Rantanen P, Laippala P. Finnish modification of the 13-item Beck depression inventory (R-BDI) in screening an adolescent population for depressiveness and positive mood. Nord J Psychiatry (in press)

18 Charman T. The stability of depressed mood in young adolescents: school-based survey. J Affect Disord 1994;30:109-16.

19 Reinherz HZ, Giaconia RM, Silverman AB, Friedman A, Pakiz B, Fros AK et al. Early psychosocial risks for adolescent suicidal ideation and attempts. J Am Acad Child Adolesc Psychiatry 1995;34:599-611.

20 Bowers L, Smith PK, Binney V. Perceived family relationships of bullies, victims and bully/victims in middle childhood. J Soc Personal Relationship. 1994;11:215-32.

21 Slee PT, Rigby K. Australian school children's self appraisal of interpersonal relations: the bullying experience. Child Psychiatry Hum Der 1993:23:273-82.

22 Rutter M, ed. Psychosocial disturbances in young people: challenges for prevention. New York: Cambridge University Press, 1995.

23 Salmivalli C. Not only bullies and victims. Participation in harassment in schoo classes: some social and personality factors. Turku, Finland: Annales Universitatis Turkuensis, 1998.

(Accepted 10June 1999)

\title{
Ethnic and sex differences in selection for admission to Nottingham University Medical School
}

\author{
David James, Lisa Driver
}

McManus's study of applications to medical school by students in the United Kingdom and the rest of the European Union ${ }^{1}$ refuelled the debate about discrimination. ${ }^{23}$ McManus showed that 18 measures were independently associated with receiving an offer. Applicants disadvantaged in selection included those from ethnic minority groups and men. ${ }^{1}$

We analysed applications to Nottingham Medical School by students from the United Kingdom and the rest of the European Union for 1997, looking at sex and ethnic group.

\section{Methods and results}

The admissions process for applicants to University of Nottingham Medical School is detailed in the school's admissions policy document, which is reviewed annually.
Copies are available to all applicants on request and obtainable from us. The process comprises four stages.

Academic stage examines whether the applicant meets the medical school's minimum academic requirement.

Questionnaire stage-Those passing the academic stage complete a questionnaire about work experience, extracurricular activities, and positions of responsibility. These responses are scored.

Statement review-The two statements (applicant's and referee's) on the application form of the applicants with the top 960 questionnaire scores are reviewed by two assessors. Insight, motivation, personality, and communication skills are scored. The 480 candidates with the top scores are selected for interview.

Interview-In an interview of 15 minutes knowledge of Nottingham and the course, insight, motivation, per-
Faculty of Medicine, Queen's Medical Centre, Nottingham NG7 2UH

David James, admissions subdean Lisa Driver, research associate

Correspondence to: Professor James david.james@ nottingham.ac.uk

BMJ 1999;319:351-2 